Check for updates

1 University of Cambridge, Cambridge, UK

2 Population Data Science, Swansea University, Swansea, UK

3 NIHR Biomedical Research Centre, University Hospitals Bristol and Weston NHS Foundation Trust University of Bristol, Bristol, UK

Correspondence to: T Ford tjf52@medschl.cam.ac.uk

Cite this as: BMJ 2021;372:n614 http://dx.doi.org/10.1136/bmj.n614 Published: 10 March 2021

\section{Mental health of children and young people during pandemic}

\author{
Deterioration is clearest among families already struggling \\ Tamsin Ford, ${ }^{1}$ Ann John, ${ }^{2}$ David Gunnell ${ }^{3}$
}

Has covid-19 and the resulting restrictions precipitated an epidemic of mental health conditions among children and young people? Many peer reviewed and non-peer reviewed studies have reported fluctuating mental health and suicide risk during the pandemic, but few focused on children and young people under the age of $18 .^{1}$ The signal to noise ratio is high and few studies include pre-pandemic measures of mental health.

Interpretation of those that do is difficult because of differences in sampling frame, respondent (parent or child), response rates, timing of data collection, and underlying trends in the prevalence of mental health conditions. ${ }^{23}$ Studies of service use are confounded by pandemic related changes in seeking help and in assessment, recognition of mental health conditions, diagnostic practice, and provision of services. ${ }^{1}$

The mental health of the UK's children and young people was deteriorating before the pandemic, while health, educational, and social outcomes for children with mental health conditions are worse than for previous cohorts..$^{-6}$ Between 2004 and 2017 anxiety, depression, and self-harm increased, particularly among teenage girls. ${ }^{7}$ Self-harm is an important risk factor for suicide, so it is not surprising that rates of suicide among the UK's children and young people also increased, ${ }^{8}$ though numbers remain low compared with other age groups-fewer than 100 people aged under 18 died by suicide each year in England between 2014 and 2016.9

Studies carried out during the pandemic suggest that although some families are coping well, others are facing financial adversity, struggling to home school, and risk experiencing vicious cycles of increasing distress. ${ }^{11011}$ Probable mental health conditions increased from $10.8 \%$ in 2017 to $16 \%$ in July 2020 across all age, sex, and ethnic groups according to England's Mental Health of Children and Young People Survey (MHCYP). ${ }^{12}$ A self-selected sample of 2673 parents recruited through social media reported deteriorating mental health and increased behavioural problems among children aged 4 to 11 years between March and May 2020 (during lockdown) but reduced emotional symptoms among 11-16 year olds. ${ }^{11}$ The more socioeconomically deprived respondents had consistently worse mental health in both surveys - a stark warning given that economic recession is expected to increase the numbers of families under financial strain. ${ }^{110}$

Deteriorating mental health is by no means uniform. A sizeable proportion of 19 ooo 8-18 year olds from 237 English schools surveyed during early summer 2020 reported feeling happier (range $25 \%$ to $41 \%$ by school year group). ${ }^{13}$ Similarly, a quarter of young people in the MHCYP survey reported that lockdown had made their life better. ${ }^{12}$ While there was no overall change in anxiety, depression, or wellbeing among roughly 1000 13-14 year olds in south west England between October 2019 and April 2020, those who were struggling at baseline significantly improved on all three measures. ${ }^{14}$

Twelve longitudinal studies of adolescents (10 in the US, one the Netherlands, one Peru), with data both before and during the pandemic (follow-up May to September 2020, when mean age was 15.4 years) detected a moderate increase in depressive symptoms. ${ }^{15}$ Age did not moderate this increase, and those living under lockdown restrictions at the time

Early data from England's National Child Mortality Database for 23 March to 17 May 2020 raised concerns about suicides among young people aged under 18 years during the first lockdown, ${ }^{16}$ although numbers were too small ( 25 deaths) to be definitive. A more reassuring picture emerged from Japan, where suicide rates in children under 20 years seemed unchanged up to May 2020. ${ }^{17}$ Although the English database shows the incidence of child suicide has returned to pre-pandemic levels (www.ncmd.info/, personal communication), more recent data from Japan flag a concerning rise in children and adolescents during the second wave and resulting school closures. ${ }^{18}$

The incidence of self-harm recorded in primary care was substantially lower than expected for 10-17 year olds in April 2020 but returned to pre-pandemic levels by September 2020. ${ }^{19}$ Similar patterns were detected for all mental health referrals in England, ${ }^{20}$ with reductions in urgent psychiatric presentations reported across Europe, ${ }^{21}$ suggesting possible unmet need.

The national referral statistics for eating disorders in England show a doubling in the number of urgent referrals during 2020 and a smaller increase in non-urgent referrals. ${ }^{22}$ Known triggers for self-harm and poor mental health are aggravated by pandemic restrictions, including separation from friends, arguments with parents, unresolvable arguments on social media, strained finances, academic stress, and feelings of isolation. School closures are particularly difficult for families facing other adversities. ${ }^{121323-25}$

The evolving consequences of the pandemic are set against longstanding concerns about deteriorating mental health among children and young people, and the inadequacy of service provision. Although children are at lowest risk of death from covid-19, concerning signals remain about the pandemic's effects on their mental health, which are unevenly of follow- up fared worse. 
experienced across different age groups and socioeconomic circumstances. $^{24} 25$

The long term effects also remain uncertain. What we do know is that education has been disrupted and many young people now face an uncertain future. ${ }^{2425}$ Policy makers must recognise the importance of education to social and mental health outcomes alongside an appropriate focus on employment and economic prospects. As "children are the living message we send to a time we will not see," ${ }^{26}$ we urgently need to improve our efforts to meet their needs and to ensure that this generation is not disproportionately disadvantaged by covid-19.

Competing interests: The $B M$ / has judged that there are no disqualifying financial ties to commercial companies. The authors declare the following other interests: TF is part of the Research Advisory Group for Place2Be, a charity providing mental health support in schools and vice-chair of the Association of Child and Adolescent Mental Health. DG is a member of the National Suicide Prevention Strategy Advisory Group (England) and Samaritans policy, partnerships, and research committee. The BM/policy on financial interests is here: https://www.bmi.com/sites/default/files/attachments/re-

sources/2016/03/16-current-bmi-education-coi-form.pdf.

Provenance and peer review: Commissioned; not externally peer reviewed.

1 Newlove-Delgado T, McManus S, Sadler K, etalMental Health of Children and Young People group. Child mental health in England before and during the COVID-19 lockdown. Lancet Psychiatry 2021;:S2215-0366(20)30570-8.pmid: 33444548

2 Thombs BD, Bonardi O, Rice DB, etal. Curating evidence on mental health during COVID-19: a living systematic review. J Psychosom Res 2020:133:110113.

doi: 10.1016/j.jpsychores.2020.110113 pmid: 32354463

3 Collishaw S. Annual research review: secular trends in child and adolescent mental health. J Child Psychol Psychiatry 2015;56:370-93. doi: 10.1111/jcpp.12372 pmid: 25496340

4 Sellers R, Warne N, Pickles A, Maughan B, Thapar A, Collishaw S. Cross-cohort change in adolescent outcomes for children with mental health problems. J Child Psychol Psychiatry 2019;60:813-21. doi: 10.1111/jcpp.13029 pmid: 30989670

5 Pitchforth JM, Viner RM, Hargreaves DS. Trends in mental health and wellbeing among children and young people in the UK: a repeated cross-sectional study, 2000-14. Lancet Psychiatry 2016;388:S93. doi: 10.1016/S0140-6736(16)32329-7

6 McManus S, Gunnell D, Cooper C, etal. Prevalence of non-suicidal self-harm and service contact in England, 2000-14: repeated cross-sectional surveys of the general population. Lancet Psychiatry 2019;6:573-81. doi: 10.1016/S2215-0366(19)30188-9 pmid: 31175059

7 Sadler K, Vizard T, Ford T, Goodman A, Goodman R, McManus S. The mental health of children and young people in England 2017: trends and characteristics. Health and Social Care Information Centre, 2018. https://digital.nhs.uk/data-and-information/publications/statistical/mental-healthof-children-and-young-people-in-england/2017/2017

8 Bould H, Mars B, Moran P, Biddle L, Gunnell D. Rising suicide rates among adolescents in England and Wales. Lancet 2019;394:116-7. doi: 10.1016/S0140-6736(19)31102-X pmid: 31227370

9 Rodway C, Tham SG, Ibrahim S, Turnbull P, Kapur N, Appleby L. Children and young people who die by suicide: childhood-related antecedents, gender differences and service contact. BJPsych Open 2020;6:e49. doi: 10.1192/bjo.2020.33. pmid: 32390589

10 Petri-Romano P, Bali E, Enright J, et al. Safe model for school returns during the covid-19 pandemic. 2021. https://www.gla.ac.uk/media/Media_736441_smxx.pdf

11 Waite PD, Pearcey S, Shum A, Raw J, Patalay P, Creswell C. How did the mental health of children and adolescents change during early lockdown during the COVID-19 pandemic in the UK? PsyArXiv 2020. [Preprint.] doi: 10.31234/osf.io/t8rfxhttps://psyarxiv.com/t8rfx

12 Vizard T, Sadler K, Ford T, etal. Mental health of children and young people in England 2020 Wave 1 follow-up to the 2017 survey. Health and Social Care Information Centre, 2020, https://files.digital.nhs.uk/CB/C41981/mhcyp_2020_rep.pdf

13 Mansfield KL, Jindra C, Fazel M. The OxWell School Survey 2020. Report of preliminary findings. 2020. https://www.psych.ox.ac.uk/research/schoolmentalhealth/summary-report/preliminarysummaryreport_oxwellsurvey2020_entire_survey_2020-09-11.pdf

14 Widnall E, Winstone L, Mars B, Haworth CMA, Kidger J. Young people's mental health during the covid-19 pandemic: initial findings from a secondary school survey study in south west England. 2020. https://sphr.nihr.ac.uk/wp-content/uploads/2020/08/Young-Peoples-Mental-Health-duringthe-COVID-19-Pandemic-Report.pdf

15 Barendse M, Flannery JE, Cavanagh C, etal. Longitudinal change in adolescent depression and anxiety symptoms from before to during the COVID-19 pandemic: an international collaborative of 12 samples. PsyArXiv 2021. [Preprint.] https://psyarxiv.com/hn7us/

16 Odd D, Sleap V, Appleby L, Gunnel D, Luyt K. Child suicide rates during the covid-19 pandemic in England: real-time surveillance. National Child Mortality Database. July 2020. https://www.ncmd.info/wp-content/uploads/2020/07/REF253-2020-NCMD-Summary-Reporton-Child-Suicide-July-2020.pdf
17 Isumi A, Doi S, Yamaoka Y, Takahashi K, Fujiwara T. Do suicide rates in children and adolescents change during school closure in Japan? The acute effect of the first wave of COVID-19 pandemic on child and adolescent mental health. Child Abuse Negl 2020;110:104680.

doi: 10.1016/j.chiabu.2020.104680 pmid: 32847679

18 Tanaka T, Okamoto S. Increase in suicide following an initial decline during the covid-19 pandemic in Japan. Nat Hum Behav 2021;5:229-38. doi: 10.1038/s41562-020-01042-z pmid: 33452498

19 Carr MJ, Steeg S, Webb RT, etal. Effects of the COVID-19 pandemic on primary care-recorded mental illness and self-harm episodes in the UK: a population-based cohort study. Lancet Public Health 2021;6:e124-35. doi: 10.1016/S2468-2667(20)30288-7 pmid: 33444560

20 Ougrin D, Wong HC, Vaezinejad M, et al. Pandemic-related emergency psychiatric presentations for self-harm of children and adolescents in 10 countries (PREP-Kids): a retrospective international cohort study. SSRN 210ctober 2020. [Preprint.] https://papers.ssrn.com/sol3/papers.cfm?abstract_id=3692541

21 Chen S, Jones PB, Underwood BR, etal. The early impact of COVID-19 on mental health and community physical health services and their patients' mortality in Cambridgeshire and Peterborough, UK. J Psychiatr Res 2020;131:244-54. doi: 10.1016/j.jpsychires.2020.09.020 pmid: 33035957

22 NHS England. CYP-ED waiting times time-series. 2021. https://www.england.nhs.uk/statistics/wpcontent/uploads/sites/2/2021/02/CYP-ED-Waiting-Times-Timeseries-Q3-2020-21.xls

23 Thompson EC, Thomas SA, Burke TA, etal. Suicidal thoughts and behaviors in psychiatrically hospitalized adolescents pre- and post- COVID-19: a historical chart review and examination of contextual correlates. J Affect Disord Rep 2021;4:100100; Epub ahead of print. doi: 10.1016/j.jadr.2021.100100 pmid: 33558865

24 Viner R, Russel S, Saulle R, etal. Impacts of school closures on physical and mental health of children and young people: a systematic review. medRxiv 2021.02.10.21251526; doi: 10.1101/2021.02.10.21251526

25 Lewis SJ, Munro APS, Smith GD, Pollock AM. Closing schools is not evidence based and harms children. BMJ 2021;372:n521. doi: 10.1136/bmj.n521 pmid: 33622685

26 Postman N. The disappearance of childhood. Delacorte Press, 1982

This article is made freely available for use in accordance with BMJ's website terms and conditions for the duration of the covid-19 pandemic or until otherwise determined by BMJ. You may use, download and print the article for any lawful, non-commercial purpose (including text and data mining) provided that all copyright notices and trade marks are retained. 